\title{
Retinoic Acid Enhances Growth of Human Early Erythroid Progenitor Cells In Vitro
}

\author{
Dan Douer and H. Phillip Koeffler, Department of Medicine Division of \\ Hematology/Oncology University of California at Los Angeles School of \\ Medicine, Los Angeles, California 90024
}

A B S TRACT We studied the effect of retinoic acid on the clonal proliferation of normal human early erythroid progenitor cells in vitro. Normal peripheral blood cells were cultured in methylcellulose with erythropoietin and the number of burst-forming unitserythroid (BFU-E) colonies were scored on day 12 of culture. All-trans retinoic acid increased the number of colonies in a dose-response fashion. Maximal stimulation occurred at $30 \mathrm{nM}$ retinoic acid, which increased the number of BFU-E by a mean of $225 \pm 25 \%$ $( \pm \mathrm{SE})$ over plates containing erythropoietin alone. Colony formation increased even in the presence of maximally stimulating concentrations of erythropoietin. The 13-cis retinoic acid stimulated BFU-E proliferation in a parallel manner as the trans analogue, while retinol (vitamin A) did not affect clonal growth. This data supports further the thesis that retinoic acid, in addition to its known effect on epithelial cells, may be involved in the growth of normal hematopoietic cells.

\section{INTRODUCTION}

Vitamin A, its metabolites and analogues (retinoids), are involved in the normal growth and differentiation of epithelial tissues $(1,2)$. Several reports suggest that retinoids may also influence the growth and differentiation of hematopoietic cells. Earlier morphological studies found a reduction of hematopoietic cells in the

Dr. Koeffler is a scholar of the Leukemia Society of America.

Received for publication 30 November 1981 and in revised form 7 January 1982. bone marrow of vitamin A-deficient animals $(3,4)$. We have recently shown that retinoic acid and other retinoids enhance the growth in vitro of normal human granulocyte-macrophage progenitors (colony-forming units, CFU-GM) ${ }^{1}(5)$. Anemia has been reported to develop in a group of healthy men who were given ample essential nutrients except vitamin A (6), suggesting that retinoids might be involved in erythropoiesis.

As part of our studies to understand the effect of retinoids on hematopoietic cells, we investigated their effect in vitro on normal human early erythroid progenitor cells. We report that retinoic acid markedly increases the number of burst-forming units-erythroid (BFU-E) cultured from normal human peripheral blood.

\section{METHODS}

Retinoids. All-trans retinoic acid, retinol (Sigma Chemical Co., St. Louis, MO), and 13-cis retinoic acid (a gift from Dr. B. Pawson, Hoffmann-La Roche, Inc., Nutley, NJ) were stored at $-20^{\circ} \mathrm{C}$. They were dissolved in $100 \%$ ethanol at $3 \mathrm{mM}$ and diluted with phosphate-buffered saline (PBS) before use. Retinoids are degraded upon exposure to light; therefore, all experiments were performed in subdued light, and all tubes containing retinoids were covered with aluminum foil.

$B F U-E$ culture technique. Human peripheral blood from normal volunteers was collected into syringes coated with preservative-free heparin. BFU-E erythroid were assayed according to the method of Bersch and Golde (7). Briefly, the blood was centrifuged in Wintrobe tubes, and the buffy

\footnotetext{
${ }^{1}$ Abbreviations used in this paper: BFU-E, burst-forming units-erythroid; CFU-GM, colony-forming units-granulocyte-macrophage progenitors.
} 
coat cells were removed and washed. The red cells were lysed with tris- $\mathrm{NH}_{4} \mathrm{Cl}$. A total of $1-2 \times 10^{5}$ cells $/ \mathrm{ml}$ were suspended in $0.8 \%$ methylcellulose with alpha-modified Minimum Essential Medium (Flow Laboratories, Inc., Rockville, MD), containing $30 \%$ fetal calf serum, $5 \%$ conditioned medium from a $\mathrm{T}$ lymphocyte cell line, which is a rich source of erythroid-potentiating activity (8), $0.1 \mathrm{mM}$ alpha-thioglycerol, penicillin, streptomycin, and erythropoietin (step III, Connaught, Ontario, Canada). The cells were plated in $35-\mathrm{mm}$ petri dishes in $1-\mathrm{ml}$ portions that contained $0.1 \mathrm{ml}$ of PBS. Ethanol concentrations equivalent to that present in the final concentration of retinoic acid had no effect on BFU$\mathrm{E}$. The cultures were incubated $12 \mathrm{~d}$ in a humidified atmosphere containing $5 \% \mathrm{CO}_{2}$, and air and erythroid colonies of 40 cells or more were scored by an inverted microscope. Each experiment was performed in triplicate dishes per point.

\section{RESULTS}

Normal human peripheral blood cells $\left(2 \times 10^{5}\right.$ cells/ dish) from various normal individuals formed 29-93 BFU-E colonies when plated with $0.5 \mathrm{U} / \mathrm{ml}$ of erythropoietin. All-trans retinoic acid in a dose-dependent fashion increased the number of BFU-E (Fig. 1). Maximal stimulation occurred at a retinoic acid concentration of $30 \mathrm{nM}$. At this concentration of retinoic acid the number of BFU-E increased by a mean of $225 \pm 25 \%$ $( \pm \mathrm{SE}$ ) with a range of $172-256 \%$ as compared with control plates containing $0.5 \mathrm{U}$ of erythropoietin alone. The mean results represent the means of six separate experiments using blood cells from a different normal individual for each experiment.

We examined the effect of two other retinoids on BFU-E. 13-Cis retinoic acid increased the number of BFU-E in a manner parallel to all-trans retinoic acid

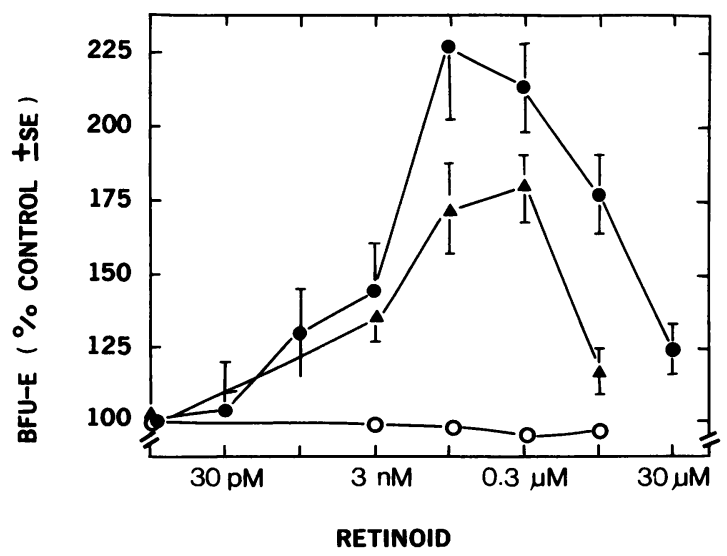

FigURE 1 Effect of all-trans retinoic acid (๑), 13-cis retinoic acid $(\Delta)$, and retinol (vitamin $A, O$ ) on BFU-E formation in the presence of $0.5 \mathrm{U} / \mathrm{ml}$ of erythropoietin. Results are expressed as a mean $\pm S E$ percentage of control plates that contain no retinoic acid. Each point represents the mean of six separate experiments using a different normal individual for each experiment.
(Fig. 1). Maximal stimulation of $180 \%$ over control plates occurred at $30 \mathrm{nM}, 13$-cis retinoic acid. Retinol (vitamin A), which is the parent compound of the group, had no effect on BFU-E at concentrations ranging from $3 \mathrm{nM}$ to $3 \mu \mathrm{M}$.

We tested the ability of all-trans retinoic acid (30 $\mathrm{nM})$ to enhance erythroid colony formation in the presence of various erythropoietin concentrations (Fig. 2). Retinoic acid increased BFU-E formation at all concentrations of erythropoietin. Colony formation increased even in the presence of maximally stimulating concentrations of erythropoietin (2-5 U/plate). In our culture system BFU-E colonies grow in the absence of exogenous erythropoietin (8) and these colonies were also stimulated by retinoic acid.

\section{DISCUSSION}

The present study shows that both all-trans and 13-cis retinoic acid enhance human BFU-E formation in vitro. Retinoic acid also increased human CFU-GM formation (5). This data suggests that retinoids, in addition to their known effect on epithelial cells, may be involved in growth of hematopoietic tissue. In contrast, retinoic acid recently was found to have antileukemic effects in vitro: this agent induced differentiation of human promyelocytic leukemia cells $(9,10)$, and we have found that it inhibits the clonal growth of human myeloid leukemia cells from patients and cell lines (11). Careful in vivo studies are now necessary to con-

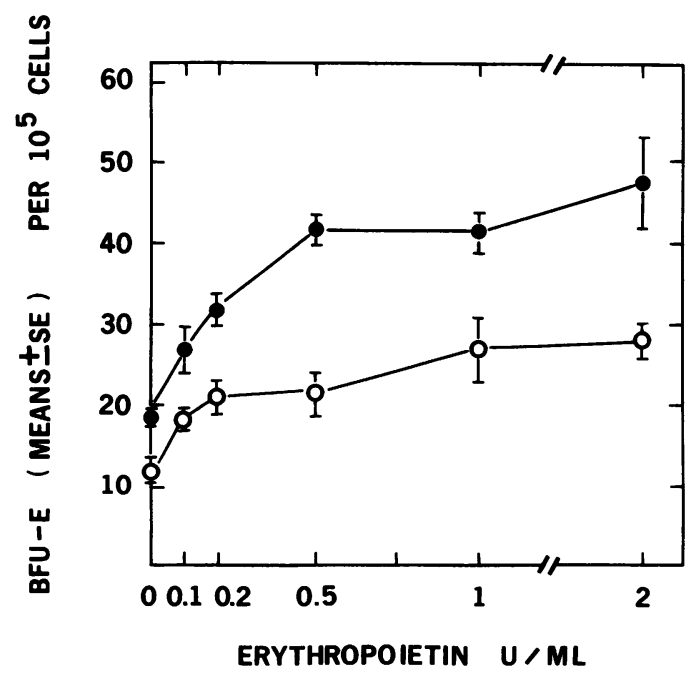

FIGURE 2 Effect of all-trans retinoic acid on number of peripheral blood BFU-E induced by different concentrations of erythropoietin. Control (O); retinoic acid ( $30 \mathrm{nM}, 0)$. Each point represents the mean number of BFU-E from two normal individuals studied on two separate occasions. Each experiment was performed with triplicate dishes per point. 
clude that retinoids have a physiological effect on hematopoietic tissue.

We did not observe a stimulatory effect in vitro of retinol (vitamin A) on either BFU-E or CFU-GM formation (5). Vitamin A can be metabolized to retinoic acid, and it has been proposed that in some biological systems the latter substance may be an active metabolite of vitamin A (12). The lack of effect of vitamin $A$ in vitro on erythroid and granulocyte-macrophage progenitor cells might reflect the inability of our culture systems to metabolize vitamin A to retinoic acid.

\section{ACKNOWLEDGMENTS}

We thank Dr. Beverly Pawson from Hoffmann-La Roche, Inc., Nutley, NJ for providing the 13-cis retinoic acid. We would also like to thank Regina Simon and Anna Holland for their help in the preparation of this manuscript.

This work was made possible, in part, by the Bruce Fowler, Jr. Memorial Fund.

\section{REFERENCES}

1. Lotan, R. 1980. Effects of vitamin A and its analogs (retinoids) on normal and neoplastic cells. Biochim. Biophys. Acta. 605: 33-91.

2. Spron, M. B., N. M. Dunlop, D. L. Newton, and J. M. Newton. 1976. Prevention of chemical carcinogenesis by vitamin $A$ and its synthetic analogs (retinoids). Fed. Proc. 35: 1332-1338.

3. Findlay, G. M., and R. D. McKenzie. 1922. The bone marrow in deficiency diseases. J. Pathol. Bacteriol. 25: 402-403.

4. Wolbach, S. B., and P. R. Howe. 1925. Tissue changes following deprivation of fat soluble A vitamin. J. Exp. Med. 42: 753-777.

5. Douer, D., and H. P. Koeffler. 1982. Retinoic acid enhances colony-stimulating factor induced clonal growth of normal human myeloid progenitor cells in vitro. Exp. Cell. Res. In press.

6. Hodges, R. E., H. E. Sauberlich, J. E. Canham, D. L. Wallace, R. B. Rucker, L. A. Mejia, and M. Mohanram. 1978. Hematopoietic studies in vitamin A deficiency. Am. J. Clin. Nutr. 31: 876-885.

7. Bersch, N., and D. W. Golde. 1978. Growth of murine and human erythroid colonies in vitro. In In Vitro Aspects of Erythropoiesis. M. J. Murphy, Jr., C. Peschle, A. S. Gordon, and E. A. Mirand, editors. Springer-Verlag, New York. 252-253

8. Golde, D. W., N. Bersch, S. G. Quan, and A. J. Lusis. 1980. Production of erythroid-potentiating activity by a human T-lymphoblast cell line. Proc. Natl. Acad. Sci. U. S. A. 77: 593-596.

9. Breitman, T. R., S. E. Selonick, and S. J. Collins. 1980. Induction of differentiation of the human promyelocytic leukemia cell line (HL-60) by retinoic acid. Proc. Natl. Acad. Sci. U. S. A. 77: 2936-2940.

10. Breitman, T. R., S. J. Collins, and B. R. Keene. 1981. Terminal differentiation of human promyelocytic leukemia cells in primary culture in response to retinoic acid. Blood. 57: 1000-1004.

11. Douer, D., and H. P. Koeffler. 1982. Retinoid acid: inhibition of the clonal growth of human myeloid leukemia cells. J. Clin. Invest. 69: 277-283.

12. De Luca, H. F. 1979. Retinoic acid metabolism. Fed. Proc. 38: 2519-2523. 